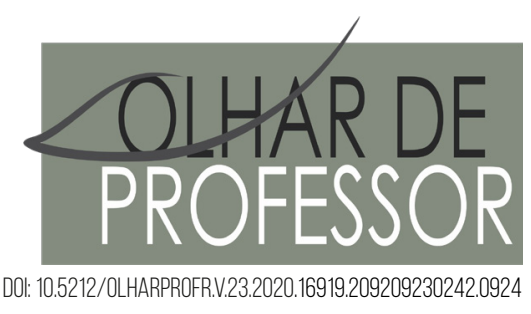

\title{
FEMINISMO SOCIALISTA E PEDAGOGIA DAS MULHERES OPRIMIDAS: UM CAMINHO LIBERTADOR EM TEMPOS DE NEOLIBERALISMO
}

\author{
SOCIALIST FEMINISM AND A PEDAGOGY OF OPPRESSED WOMEN: A LIBERATORY PATH IN TIMES OF \\ NEOLIBERALISM
}

\author{
FEMINISMO SOCIALISTA Y PEDAGOGÍA DE LAS MUJERES OPRIMIDAS: UN CAMINO LIBERADOR EN \\ TIEMPOS DE NEOLIBERALISMO
}

MIRIAM FURLAN BRIGHENTE*

\begin{abstract}
Resumo: Vivemos num sistema capitalista neoliberal que defende o individualismo e a competição e onde as ações humanas são pautadas pela ideologia do livre mercado. Para superar essa lógica opressiva e exploradora, proponho um diálogo entre o feminismo socialista e uma pedagogia das mulheres oprimidas, que é uma alternativa coletiva e cooperativa, forjada com e não para as mulheres. O objetivo desta investigação teórica é estender a teoria de Paulo Freire para incorporar o feminismo socialista e, assim, construir uma educação popular feminista e socialista. Para construir um novo mundo, protestos massivos, mas também trabalho de educação popular, socialista e feminista com pequenos grupos tem se tornado cada vez mais urgente em tempos de neoliberalismo, como as práticas desenvolvidas no Brasil, Canadá, Estados Unidos e Bolívia. É lendo o mundo, ou seja, o conhecimento criado socialmente, e lendo a palavra, o conhecimento sistematizado, que as mulheres podem se tornar críticas de seu contexto e lutar por uma justiça social revolucionária.
\end{abstract}

Palavras-chave: Feminismo socialista. Pedagogia das mulheres oprimidas. Educação popular. Neoliberalismo.

Abstract: We live in a neoliberal capitalist system that defends individualism and competition and where human actions are guided by the ideology of the free market. To overcome this oppressive and exploitative logic, I propose a dialogue between socialist feminism and a pedagogy of oppressed women as a collective and cooperative alternative, forged with and not for women. The objective of this theoretical investigation is to extend Paulo Freire's theory to incorporate socialist feminism and, thus, build popular feminist and socialist education. To build a new world, massive protests, but also popular, socialist and feminist education work with small groups has become increasingly urgent in times of neoliberalism, such as the practices developed in Brazil, Canada, the United States and Bolivia. It is by reading the world, that is, knowledge created socially, and reading the word, systematized knowledge, that women can become critical of their context and fight for revolutionary social justice.

Keywords: Socialist feminism. Pedagogy of oppressed women. Popular education. Neoliberalism.

Resumen: Vivimos en un sistema capitalista neoliberal que defiende el individualismo y la competencia y donde las acciones humanas están guiadas por la ideología del libre mercado. Para superar esta lógica opresiva y explotadora, propongo un diálogo entre el feminismo socialista y una pedagogía de las mujeres oprimidas, que es una alternativa colectiva y cooperativa, forjada con y no para las mujeres. El objetivo de esta investigación teórica es extender la teoría de Paulo Freire para incorporar al feminismo socialista, y así construir una educación popular feminista y socialista. Para construir un mundo nuevo, las protestas masivas, pero también el trabajo de educación popular, socialista y feminista con pequeños grupos se ha vuelto cada vez más urgente en tiempos de neoliberalismo, como las prácticas desarrolladas en Brasil, Canadá, Estados Unidos y Bolivia. Es leyendo el

\footnotetext{
${ }^{*}$ Doutoranda em Educational Studies na Eastern Michigan University (EMU), nos Estados Unidos. Doutora e Mestra em Educação pela PUC-PR. Atua como Research Doctoral Fellow no Department of Teacher Education. E-mail: mfurlanb@emich.edu
} 
mundo, es decir, el conocimiento creado socialmente, y leyendo la palabra, el conocimiento sistematizado, que las mujeres pueden volverse críticas de su contexto y luchar por una justicia social revolucionaria.

Palabras clave: Feminismo socialista. Pedagogía de las mujeres oprimidas. Educación popular. Neoliberalismo.

\section{INTRODUÇ̃̃O: A ESCOLHA POR UMA EDUCAÇÃO POPULAR, FEMINISTA E SOCIALISTA}

A luta das mulheres pela libertação tem ocorrido histórica e geograficamente de maneiras diferentes; no entanto, algumas vozes continuam a ser hegemônicas e supremas: masculinas, brancas, ocidentais, alfabetizadas, heterossexuais, capacitistas, cristãs, elitistas e principalmente as vozes vindas do Um Terço do Mundo e Primeiro Mundo/Norte ${ }^{1}$. Quando os discursos, a teoria e a prática produzidos por essas vozes prevalecem, não há espaço para um diálogo genuíno. Como antídoto, proponho um diálogo entre o feminismo socialista e uma pedagogia das mulheres oprimidas, com base na teoria do educador brasileiro Paulo Freire. Além disso, procuro estender a teoria de Freire para incorporar o feminismo socialista. Assim, utilizo a teoria e a prática dessas duas abordagens para denunciar como, em tempos de neoliberalismo, as mulheres estão presas nas estruturas opressivas do capitalismo e do patriarcado, mas também para anunciar uma alternativa libertadora e coletiva: a construção de uma educação popular, feminista e socialista como contraponto ao neoliberalismo.

O neoliberalismo passou a fazer parte da política econômica em 1979 com Margaret Thatcher no Reino Unido e em 1980 com Ronald Reagan nos Estados Unidos. Este projeto político e econômico pode ser definido "como um conjunto de premissas políticas que favorecem as corporações, como inseparáveis da globalização e do imperialismo [...] é uma filosofia que vê as trocas de mercado como um guia para toda ação humana” (DEAN, 2009, p. 51, tradução da autora). A ideologia neoliberal é, além disso, baseada na competição e que todos podem vencer, o que é uma "fantasia do livre mercado" (p. 55, tradução da autora), pois sempre haverá "vencedores e perdedores" (p. 57, tradução da autora). Neoliberalismo também é entendido pelo feminismo socialista como um sistema de valores políticos que substitui o liberalismo do bem-estar e a justiça distributiva pela ideologia individualista do livre mercado.

Diante desses desafios, realizo uma investigação teórica e aponto como o feminismo socialista e uma pedagogia das mulheres oprimidas, caminhos revolucionários, precisam ser forjados com e não para as mulheres neste atual momento econômico e político. Gostaria de enfatizar como ponto de entrada que procuro compreender as situações de opressão das mulheres através das lentes interseccionais de classe, gênero/sexo, raça/etnia e capacistismo. Assim, eu me apoio em feministas conhecidas por seus argumentos contra o patriarcado capitalista, neoliberalismo e opressão como Davis (1983), Dean (2009), Eisenstein (1979a, 1979b, 1979c), Fraser (2013), Jaggar (1988) e Young (2011). As décadas de 1980-1990 propiciaram uma discussão fecunda desses conceitos. Também me baseio nos argumentos de Freire, que escreveu sua obra revolucionária, Pedagogia do Oprimido em 1968, em sua língua nativa, o português. Esta obra foi traduzida para o inglês em 1970.

Não estou aqui reciclando velhas teorias, mas reinterpretando-as dentro de nossa situação econômica e social: um sistema capitalista neoliberal. No entanto, podemos nos perguntar: Por que essas teorias? Porque elas precisamente criticam o modo de produção capitalista neoliberal e o que ele acarreta: racismo, xenofobia, patriarcado, capacistismo, sexismo, classismo entre outros, inclusive, e principalmente, nos dias de hoje. Certamente reconheço todos os avanços da luta feminista e educacional, mas como afirma Eisenstein (2019): “Tudo muda e nada muda” (p. 23, tradução da autora). Para pensar em práticas libertadoras, alternativas e revolucionárias, precisamos repensar a teoria feminista existente porque "a teoria nos permite pensar sobre novas possibilidades” (EISENSTEIN, 1979a, p. 34, tradução da autora). Também é importante considerar o momento histórico, social e econômico em que vivemos, pois “a teoria

\footnotetext{
${ }^{1}$ Não gosto de usar as diferenciações Primeiro Mundo e Terceiro Mundo, uma vez que as fronteiras são nebulosas. Como Eisenstein (2019) observou: «Distinções como primeiro e terceiro mundo ainda se aplicam, e também não. O terceiro mundo vive na cidade de Nova York, e o Kentucky Fried Chicken opera no Quênia” (p. 22, tradução da autora). Por esta razão, utilizo os conceitos Um terço/Dois terços do Mundo (“One-Third/Two Thirds World”) e Primeiro Mundo/Norte e Terceiro Mundo/Sul ("First World/North and Third World/South”) para evitar binarismos e uma linguagem hegemônica, colonialista e hierárquica. Esses termos são usados por Mohanty (2003, p. 227) que se inspira na obra Grassroots Post-Modernism: Remaking the Soil of Cultures, publicada em 1998 por Gustavo Esteva e Madhu Suri Prakash.
} 
nos dá uma descrição dos problemas que enfrentamos, fornece uma análise das forças que mantêm a vida social, define os problemas que devemos concentrar e atua como um conjunto de critérios de avaliação das estratégias que desenvolvemos" e, acima de tudo, "a própria teoria pode ser uma força de mudança" (HARTSOCK, 1979, p. 57, tradução da autora).

Para tanto, alinho-me com Jaggar (1988) para afirmar que o feminismo socialista é "a promessa mais convincente de construção de uma teoria e prática adequadas para a libertação das mulheres” (p. 123, tradução da autora) e com Fraser (2013) que argumentou que "A teorização socialista-feminista [...] ainda me parece oferecer nossa melhor esperança para esclarecer as perspectivas para a justiça de gênero no período presente” (p. 210, tradução da autora). Além disso, sugiro um diálogo com Freire (2005) que explicou que assim como os opressores precisam de uma teoria para justificar sua opressão, como a ação antidialógica e seus elementos de 1) conquista, 2) divisão, 3) manipulação e 4) invasão cultural; os oprimidos (p. 157-191), para se libertarem, precisam de uma teoria, como a ação dialógica e seus componentes de 1) colaboração, 2) união, 3) organização e 4) síntese cultural (p. 191-213). Como resultado dessas duas abordagens, temos uma pedagogia popular, feminista e socialista que busca acabar com a opressão vivida pelas mulheres e inaugurar um novo mundo.

Tanto o feminismo socialista quanto uma pedagogia das mulheres oprimidas buscam transformar 0 sistema capitalista, sexista, capacitista e racista ao mesmo tempo em que almejam o advento de um novo mundo: justo e livre de opressão. Isso não é possível sem uma educação libertadora. Não estou falando de uma educação tradicional que segue um currículo pré-fabricado, criado e executado de cima para baixo, mas de uma educação conscientizadora, libertadora, feminista, socialista e popular, criada coletivamente em uma relação horizontal, dialógica e democrática. No final, não apenas a opressão de uma classe social deve desaparecer, mas também as opressões de raça/etnia, gênero/sexo e de ordem capacitista.

É por isso que estendo a teoria de Freire para incorporar o movimento das mulheres e criar um diálogo revolucionário entre as obras das feministas socialistas e a obra do educador e filósofo brasileiro. Como hooks (1993) corretamente observou: «Peguei fios da obra de Paulo e os teci naquela versão da pedagogia feminista que acredito que meu trabalho como escritora e professora incorpora” (p. 124, tradução da autora). Hooks (1993) explica que se identificou com a obra de Freire por ser uma garota negra que trabalhava no campo no sul dos Estados Unidos e acabou se vendo nos camponeses que Freire mencionava em suas obras. O conceito de educação bancária também chamou a atenção de hooks (1993), pois ela percebeu que a educação formal não contemplava questões de sua realidade. Para este ensaio, busquei então tecer uma análise da pedagogia do(a) oprimido(a) e do feminismo socialista. Dito isso, é importante saber o que significa um feminismo socialista.

\section{FEMINISMO SOCIALISTA: SUPERANDO A ORDEM CAPITALISTA NEOLIBERAL E PATRIARCAL}

O feminismo socialista, que surgiu nas décadas de 1960 e 1970, pretendia criar uma teoria e prática política que "sintetizasse as melhores ideias do feminismo radical e da tradição marxista e que simultaneamente escaparia dos problemas associados a cada um” (JAGGAR, 1988, p. 123, tradução da autora), o que significaria então estar "comprometido com a compreensão do sistema de poder derivado do patriarcado capitalista” (EISENSTEIN, 1979a, p. 5, tradução da autora). Nesse sentido, é necessário ir além da análise de classe marxista devido ao fato de que Marx não percebeu (ou não reconheceu) que a reprodução biológica das mulheres e os papéis maternos criam uma opressão de gênero/sexo, tais como ser mãe, criar os filhos e fazer o trabalho doméstico sem receber salário ou ser paga por esse trabalho (EISENSTEIN, 1979a).

É por isso que a exploração de mulheres e homens não pode ser analisada da mesma maneira. É fundamental também expandir a análise do feminismo radical, que considera as "semelhanças na experiência de todas as mulheres” (JAGGAR, 1988, p. 133, tradução da autora) e considera a análise de classe no mesmo nível de gênero/sexo. Isto é, indo além de uma análise marxista e também de uma teoria feminista radical, o feminismo socialista entende a opressão das mulheres a partir da divisão gênero/ sexo do trabalho produzida pelas relações sociais capitalistas. Eisenstein (2019) expandiu seu conceito de feminismo socialista e falou de abolicionismo, para lutar pelo fim do racismo misógino. É necessário, 
portanto, aprender sobre as relações entre o capitalismo e o patriarcado se quisermos mudar as estruturas de opressão já que esses conceitos estão interligados e se reforçam mutuamente.

O feminismo socialista, por exemplo, busca estratégias para superar o capitalismo e a hegemonia masculina e, assim, criar outras formas de consciência e atividades políticas: "as lutas comunitárias, a organização das mulheres contra sua alienação no trabalho assalariado, a cultura feminista e as tentativas de reestruturação das relações sexuais e de educação dos filhos” (JAGGAR, 1988, p. 335). Esta luta deve ser coletiva, democrática e contra todas as formas possíveis de opressão; esta não é uma luta autoritária ou hierárquica. Afinal, "uma organização hierárquica, não democrática, sexista e racista pode alcançar apenas uma 'revolução hierárquica', não democrática, sexista e racista” (JAGGAR, 1988, p. 338, tradução da autora). Com base nisso, o feminismo socialista nos dá esperança de uma justiça social revolucionária, tais como formas socialmente justas de trabalho e distribuição igualitária de bens e serviços, o que de fato não ocorre plenamente num sistema neoliberal. Além disso, essa ordem social e econômica atual exclui, oprime e explora as mulheres de várias maneiras, como mostro a seguir.

Para entender a opressão que as mulheres sofrem, não basta entender a exploração econômica, mas também é crucial compreender a relação entre "família e sociedade, produção e reprodução" (EISENSTEIN, 1979a, p. 16, tradução da autora). A análise deve ir além das relações econômicas e incorporar análises da divisão sexual do trabalho e da opressão sexual. Eisenstein (1979a) argumentou que a opressão, ao contrário da exploração que está relacionada às relações das classes econômicas capitalistas, se aplica

Às mulheres e minorias definidas nas relações patriarcais, racistas e capitalistas. Exploração é o que acontece com homens e mulheres trabalhadoras na força de trabalho; a opressão da mulher ocorre a partir de sua exploração como trabalhadora assalariada, mas também ocorre a partir das relações que definem sua existência na hierarquia sexual patriarcal—como mãe, trabalhadora doméstica e consumidora. A opressão racial a localiza dentro da divisão racista da sociedade ao lado de sua exploração e opressão sexual (EISENSTEIN, 1979a, p. 22, tradução da autora).

Da mesma forma, Young (2011) enfatiza que "a opressão é uma categoria central do discurso político" para os movimentos sociais emancipatórios atuais nos Estados Unidos, como "socialistas, feministas radicais, ativistas indígenas americanas, ativistas negras, ativistas gays e lésbicas” (p. 39, tradução da autora). Young (2011) afirmou que a opressão tradicionalmente "significa o exercício da tirania por um grupo dominante” (p. 40, tradução da autora), mas isso mudou nas décadas de 1960 e 1970 a partir dos movimentos sociais de esquerda que passaram a defini-la como "a desvantagem e a injustiça que algumas pessoas sofrem não porque o poder tirânico as coage, mas por causa das práticas cotidianas de uma sociedade liberal bem-intencionada” (p. 41, tradução da autora). Young (2011) mencionou cinco tipos de opressão que, vale ressaltar, se cruzam: 1) exploração, relacionada ao conceito marxista de classe social; 2) marginalização, que tem como alvo as minorias; 3) ausência de poder, que se refere às pessoas que ficam de fora da classe capitalista; 4) imperialismo cultural, quando a experiência e a cultura de um grupo se tornam a norma; e, 5) violência, que está relacionada a ataques sistemáticos a grupos específicos.

Nesse contexto de exploração, marginalização, ausência de poder, submissão ao imperialismo cultural e violência, é preciso também entender como a relação assimétrica de poder entre homens e mulheres funciona. Para o feminismo socialista, os homens não são opressores per se, mas porque reproduzem as relações de poder sustentadas pelo patriarcado (EISENSTEIN, 1979c). Isso significa que os homens internalizam essa relação de poder supremo e hierárquico. Portanto, para eliminar o patriarcado, é necessário "destruir as estruturas de hierarquia sexual, racial e de classe parcialmente mantidas por meio da divisão sexual do trabalho” (EISENSTEIN, 1979c, p. 51, tradução da autora). Se os homens não tomarem consciência disso e não mudarem a si próprios, coletivamente, as relações de poder permanecerão, mesmo em uma nova sociedade após a destruição das instituições capitalistas. Após revoluções na China, Cuba e União Soviética, por exemplo, o patriarcado continuou a existir, embora de uma forma ligeiramente diferente em cada país. Por isso, seria um erro dizer que a divisão sexual do trabalho chegou ao fim nessas sociedades com a destruição do capitalismo (EISENSTEIN, 1979a). Freire (FREIRE \& SHOR, 1986) também ligou o racismo e o sexismo ao capitalismo e afirmou que seria impossível 
superá-los dentro desse modo de produção, mas que eles também não desapareceriam automaticamente em uma sociedade socialista.

Os exemplos de China, Cuba e União Soviética nos mostram que não podemos discutir o capitalismo sem discutir o racismo e o sexismo. Eisenstein (1979a, 1979c), por exemplo, usou o termo patriarcado capitalista para sustentar a posição de que capitalismo e patriarcado estão interligados e são dependentes um do outro. O patriarcado capitalista é um sistema hierárquico que explora e oprime, e essa opressão tem várias faces, geralmente interligadas: racismo, sexismo, heterossexismo, classismo e capacitismo. Um exemplo é o caso de uma mulher negra descrito por Eisenstein (1979c) durante a sociedade escravista nos Estados Unidos: “Como operária ela não podia ter uma 'fragilidade' feminina, como mulher foi 'estuprada’ em sua submissão, e como escrava ela sofreu uma condição subumana” (p. 47, tradução da autora). Como é possível ver neste exemplo, as relações de poder acontecem em vários domínios interligados, e é precisamente por isso que não podemos analisar apenas racismo ou classe social ou gênero sem fazer conexões entre eles ou sem ter uma visão interseccional.

Crenshaw (1991), por exemplo, propôs a interseccionalidade como forma de abordar de forma não dicotômica as interações entre raça, gênero e patriarcado para compreender as circunstâncias da violência contra as mulheres negras. Sobre isso, ela observou:

Uma análise interseccional argumenta que as subordinações raciais e sexuais se reforçam mutuamente, que as mulheres negras são comumente marginalizadas por uma política de raça ou de gênero, e que uma resposta política a cada forma de subordinação deve ser, ao mesmo tempo, uma resposta política a ambos. (CRENSHAW, 1991, p. 1283, tradução da autora)

Este é um ponto crucial discutido por Crenshaw (1991): raça e gênero não podem ser entendidos separadamente. As mulheres negras não podem deixar, por exemplo, de denunciar seus agressores negros para proteger sua raça, com base em “estratégias antirracistas” (p. 1252, tradução da autora), assim como seus corpos não podem ser vistos como menos valiosos e dignos do que o corpo da mulher branca em um caso de estupro ou violência doméstica. Caso contrário, seus corpos e suas vozes serão silenciadas por discursos de antirracismo e feminismo. Portanto, precisamos incorporar "diferenças intersetoriais de women of color" (p. 1265, tradução da autora), formando uma "coalizão entre homens e women of color" (p. 1299, tradução da autora). Em outras palavras, não podemos apenas exigir o acréscimo da opressão das mulheres à luta de classes. É fundamental ter uma visão integrada desse caminho libertador por meio do rearranjo e expansão do movimento feminista, o que significa que "todo problema é problema de mulher, assim como todo problema tem implicações de raça e classe” (JAGGAR, 1988, p. 340, tradução da autora).

Além disso, as mulheres precisam estar conscientes criticamente da razão de serem exploradas, marginalizadas e abusadas em várias instituições capitalistas. É tomando consciência crítica de como o capitalismo patriarcal, ou o patriarcado capitalista, apoiado pelo "liberalismo, supremacia masculina e racismo" (EISENSTEIN, 1979c, p. 48) opera em suas vidas que, as mulheres, independentemente de classe, gênero/sexo, raça/etnia e/ou capacidades corporais e psicológicas, podem e devem se engajar, juntas, em uma luta revolucionária para a emancipação de todos e todas. Por isso, não basta que o feminismo socialista lute para derrubar um ou $o$ sistema ou $a$ instituição opressora, mas abolir todos eles (JAGGAR, 1988). Para que este projeto se torne viável, uma educação das mulheres oprimidas deve ser aprimorada e construída coletivamente. As ideias de Freire, nesse sentido, podem nos ajudar.

\section{POR UMA PEDAGOGIA DAS MULHERES OPRIMIDAS À LUZ DE PAULO FREIRE}

Freire não abordou explicitamente, por não ser esse seu objetivo principal, a questão de gênero na Pedagogia do Oprimido. Devemos entender que ele escreveu este livro na década de 1960, influenciado pelas obras de Karl Marx, investigações de conflitos de classe e também pela sua experiência como homem no Nordeste do Brasil, que era, como ele disse, "uma sociedade patriarcal e machista” (FREIRE, 2014, p. 327). Freire criou uma pedagogia dos oprimidos e oprimidas por meio de uma perspectiva marxista, focando principalmente na questão da classe social, e "Marx nunca questionou a ordem sexual hierárquica 
da sociedade” (EISENSTEIN, 1979a, p. 9, tradução da autora), o que significa que a exploração da mulher não foi o principal tema analisado em suas obras. No entanto, como Jaggar (1988) afirma: "não quer dizer que [a dominação das mulheres] não possa ser explicada em termos de categorias marxistas" (p. 137, tradução da autora). Por isso não podemos descartar ou rejeitar a teoria de Freire porque ele foi influenciado por Marx. A esse respeito, Freire (2014, p. 327) afirmou que:

É com grande satisfação que admito que meu engajamento com os movimentos feministas possibilitaram-me tomar um foco mais acurado das questões de gênero. Por isso, estou em débito com as feministas norte-americanas, que chamaram minha atenção por diversas ocasiões para a discriminação de gênero.

Após a publicação da Pedagogia do Oprimido nos Estados Unidos, em 1970, Freire passou a receber cartas de feministas estadunidenses acusando-o de usar uma linguagem sexista, como usar ele, dele e homem para se referir tanto a homens quanto a mulheres (FREIRE, 2010; FREIRE, 2014). Como consequência, ele começou a pedir aos editores que não usassem linguagem sexista (FREIRE, 2009) e agradeceu às mulheres por suas críticas, porque elas o ajudaram a perceber a linguagem sexista que estava usando. Ele então começou a escrever "mulher e homem ou seres humanos" (FREIRE, 2009, p. $68)$, o que o fez revisar suas obras.

De qualquer maneira, o objetivo principal de Freire (2005) em Pedagogia do Oprimido foi apontar os aspectos de uma pedagogia dos e com os oprimidos e as oprimidas em uma relação horizontal, não vertical. Além disso, o principal objetivo de seu trabalho foi mostrar que os oprimidos e as oprimidas devem refletir sobre a opressão e suas raízes e, assim, se engajarem em sua libertação. A tarefa humanística e histórica é libertar a si e ao opressor(a), juntos(as), em comunhão. Como os(as) opressores(as) são aqueles(as) que exploram os(as) oprimidos(as), os(as) opressores(as) não podem libertar os(as) oprimidos(as) nem a si próprios(as). Vale destacar que Freire (2005) propôs uma pedagogia dos oprimidos e das oprimidas, que deve se comprometer com a práxis - agindo e refletindo criticamente - e com a transformação do mundo da opressão.

Por esse motivo, Andreola (2016) escreveu que se a mudança da grafia não vier acompanhada por uma consciência crítica e compromisso com a transformação da realidade opressora da mulher pelo homem, teremos apenas uma mudança superficial e burocrática. Ele também questionou com razão:

\begin{abstract}
Mas àquelas feministas caberia também devolver a cobrança. Aquele movimento se restringia somente à luta contra a opressão da mulher ou abraçaria também o combate contra o racismo, a guerra do Vietnã, e a dominação capitalista sobre os países centro e sul-americanos? Além disso, o problema da linguagem "masculinista", como no caso de falar ou escrever "homem", entendendo abranger homens e mulheres, é um problema plurissecular ou até plurimilenar (ANDREOLA, 2016, p. 616).
\end{abstract}

Da mesma forma, hooks (1993) argumentou que, embora a linguagem sexista de Freire possa ser identificada em seus primeiros trabalhos, outros elementos caracterizam sua teoria como libertadora, e ela afirmou: "Não há necessidade de se desculpar pelo sexismo. O próprio modelo de pedagogia crítica de Freire convida a um interrogatório crítico desta falha no trabalho dele” (p. 123, tradução da autora). No entanto, como ela ressaltou: "interrogatório crítico não é o mesmo que rejeição de uma teoria” (p. 123, tradução da autora). Nesse sentido, como bem observou Hooks (1993), não devemos descartar a obra de Freire como um todo, pois o próprio Freire discutiu elementos em suas obras que contribuem para uma educação libertadora. Por isso não basta dizer, por exemplo, que não somos sexistas ou machistas, pois o que vai fazer a diferença é a forma como agimos e refletimos sobre essa questão (FREIRE, 2001b). Igualmente, não pode haver transformação na sociedade por aqueles que se dizem progressistas se a mulher continuar a ser tratada de forma colonial (FREIRE, 2009).

Em síntese, embora Freire não tenha escrito e discutido questões de gênero, ele afirmou que jamais teria escrito Pedagogia do Oprimido se tivesse oprimido as mulheres de sua família ou aquelas com quem trabalhava (VIEZZER, 1996). Freire (2014) também deixou claro que: "Sem evitar a questão de gênero, devo dizer que os(as) leitores(as) têm alguma responsabilidade em colocar meu trabalho neste contexto 
histórico e cultural” (p. 330-331). Isso significa que ler e contextualizar sua pedagogia dos oprimidos e das oprimidas para entender a opressão contra as mulheres é possível e necessário.

Que não haja mal-entendidos aqui: embora eu também esteja usando a teoria freireana para compreender e combater a opressão contra as mulheres, não estou fazendo das obras de Freire a fonte principal. É importante para mim, como mulher sul-americana e brasileira, trazer a perspectiva latino-americana, teórica e prática, para esta discussão. Freire, certamente, nos ajuda nesse sentido, especialmente na compreensão do período da Ditadura Militar (1964-1985), que deixou feridas abertas de opressão, submissão, tortura e violência ainda não cicatrizadas no Brasil. Cabe ressaltar, no entanto, que homens e mulheres foram agentes de sua história e desmantelaram esse sistema opressor e violento. Mesmo assim, enfrentamos um grande retrocesso na política democrática no Brasil com a eleição de um presidente populista de extrema-direita, Jair Bolsonaro, em 2018. Ele ameaçou apagar, por exemplo, referências a Freire, ao feminismo e a comunidade LGBTQ dos livros didáticos (OSBORNE, 2019; SALDAÑA, 2019). Educadores também têm sido intimidados por apoiadores da extrema direita por citarem o educador brasileiro em seus textos ("Professora recebe segunda denúncia”, 2019).

As ideias de Freire nos ajudam certamente a entender o contexto histórico, político, social e cultural brasileiro, mas sobre o movimento das mulheres, Freire (1985) disse a Macedo: “a libertação das mulheres é luta delas” (p. 186, tradução da autora), afirmando que as mulheres devem criar sua própria linguagem para a libertação e não usar a linguagem dos homens para isso. Seguindo essa análise, Freire e Shor (1986) ilustraram como o sexismo ocorre nas instituições de ensino superior no Brasil e nos Estados Unidos. Depois de falar sobre os comportamentos sexistas dos alunos com as mulheres, como por exemplo, interrompê-las, e sobre a minoria não-branca ficar calada em sua sala de aula no ensino superior, Shor perguntou a Freire se o sexismo e o racismo estavam presentes nas salas de aula no Brasil. Freire (1986) respondeu: "Somos uma sociedade fortemente machista e não marxista" (p. 196). Mesmo assim, disse não ver homens falando mais do que mulheres nas universidades brasileiras. Ele lembrou que se alguns alunos do sexo masculino tentassem se impor às colegas do sexo feminino nas salas de aula brasileiras, eram imediatamente confrontados pelas mulheres. Freire recomendou a Shor, que havia dito que frequentemente restringia os alunos do sexo masculino para permitir que as mulheres falassem (FREIRE \& SHOR, 1986), para não assumir a libertação das mulheres: “As mulheres devem realizar sua própria libertação, com a contribuição de alguns homens que concordam com elas, que estão com elas em sua luta” (FREIRE \& SHOR, 1986, p. 197).

Nós, mulheres, somos as protagonistas, mas é claro que também precisamos nos unir a outras forças, gêneros, etnias e diversos corpos e mentes para alcançar a totalidade de uma revolução feminista e uma educação libertadora e socialista. As mulheres, em uma pedagogia das mulheres oprimidas, devem conscientizar-se criticamente das amarras do patriarcado, classe e raça/etnia em que estão envolvidas. Sua libertação não virá como um presente da supremacia branca, da classe capitalista ou política, ou dos homens, pai, irmão ou marido que as humilha diariamente, mas de seu próprio engajamento na luta contra este sistema opressor e repressivo. Uma forma de atingir esse objetivo seria por meio de ações de uma educação popular, feminista e socialista, como será mostrado na próxima seção deste artigo. Este trabalho de libertação deve ser popular, vindo e sendo feito pelo povo porque, como Freire (2005) observou com precisão, “Nenhuma 'ordem' opressora suportaria que os oprimidos todos passassem a dizer: 'Por quê?’” e começassem a se tornar criticamente conscientes da realidade (p. 87). Como tal, o programa de uma educação libertadora, que é, sugiro, uma educação popular, feminista e socialista, deve ser construído dialogicamente com as mulheres, pois "ao revolucionário cabe libertar e libertar-se com o povo, não conquistá-lo" (p. 98); aos educadores e educadoras, esta seria a introdução de uma pedagogia das mulheres oprimidas.

Como escreveu Boff (FREIRE, 2009) no prefácio do livro de Freire, Pedagogia da Esperança: “Enquanto houver um único ser humano oprimido no mundo, este livro terá validade.” (FREIRE, 2009, p. 8), referindo-se a Pedagogia do Oprimido e Pedagogia da Esperança como uma única obra. Com base nessa afirmação, e em um momento em que temos mulheres trabalhadoras, camponesas, negras, indígenas, queer e mulheres com deficiência sendo excluídas dos espaços públicos e políticos, mais do que nunca, uma pedagogia das mulheres oprimidas é urgente e crucial. Essa concepção de mundo baseada na teoria de Freire permanece real, concreta e viva porque ainda vivemos sob o mesmo modo de produção 
capitalista em que ele viveu: uma estrutura que é construída sobre o lucro da opressão e da exploração das pessoas, principalmente os mais vulneráveis. Precisamos é claro, como Andreola (2016) sugeriu, recriar o pensamento de Freire e não repeti-lo, o que era uma exigência do próprio Freire.

Por esta razão, a educação filosófica e revolucionária de Freire deve ser uma leitura obrigatória para todos e todas que lutam por uma sociedade mais justa, mais saudável e mais bonita, sejam docentes ou discentes, líderes revolucionárias(os) ou membros de uma comunidade. Depois de compreendermos o que significa o feminismo socialista e sua proposta de superação de um capitalismo patriarcal e a proposta da pedagogia dos oprimidos e das oprimidas, veremos como isso pode se concretizar nas práticas cotidianas dentro da lógica neoliberal.

\section{RUMO A UMA EDUCAÇ̃̃O POPULAR, FEMINISTA E SOCIALISTA COMO ANTÍDOTO AO PROJETO NEOLIBERALISTA}

O neoliberalismo promove divisão e competição; é um projeto que beneficia a classe capitalista e que valoriza o status quo ao invés de questioná-lo e transformá-lo. Tudo vira mercadoria: saúde, educação, moradia e transporte; bens e serviços deixam de ser públicos e gratuitos, pois a privatização é um dos objetivos principais do capitalismo neoliberal globalizado. O discurso neoliberal é sustentado pela ideologia fatalista de que nada pode ser feito contra o status quo, a não ser nos adaptarmos a ele já que as condições materiais e históricas não são vistas como passíveis de mudanças. Como Freire (2002, p. 22) observou:

A ideologia fatalista, imobilizante, que anima o discurso neoliberal anda solta no mundo. Com ar de pós-modernidade, insiste em convencer-nos de que nada podemos contra a realidade social que, de histórica e cultural, passa a ser ou a virar 'quase natural'. Frases como 'a realidade é assim, que podemos fazer?” ou ‘o desemprego no mundo é uma fatalidade [...]' expressam bem o fatalismo desta ideologia e sua indiscutível vontade imobilizadora.

Dentro dessa doutrina política e econômica, o objetivo da educação (bancária e desumanizante) é ajustar os educandos e educandas a sociedade para que eles e elas aceitem as condições socioeconômica e cultural como elas são. Para os neoliberais da educação não há o que fazer, apenas providenciar “o treino técnico indispensável à adaptação do educando, à sua sobrevivência” (FREIRE, 2002, p. 22), para que as elites econômica e política continuem exercendo e naturalizando suas riquezas e privilégios, seu poder autoritário e hierárquico, seu pensamento binário, branco, masculino e heteronormativo, e sua arrogância de Um Terço do Mundo e Primeiro Mundo/Norte. No entanto, Freire (2002) nos ensinou que a história é possibilidade e não determinação; somos seres inconclusos e temos uma vocação ontológica para o ser mais. É justamente isso que nos une para lutar em prol de um mundo mais justo e mais bonito, a favor da ética do ser humano, não da ética do mercado.

Giroux, professor norte-americano e pesquisador da pedagogia freireana, considera o neoliberalismo uma das ideologias mais perigosas do século XXI para a economia global devido ao seu "ataque à democracia, aos bens públicos, ao estado de bem-estar e aos valores não mercantilizados. No neoliberalismo, tudo está à venda ou é saqueado para o lucro" (GIROUX, 2004, p. 495, tradução da autora). Como o mercado organiza a sociedade, ele acaba inclusive regulando as relações humanas. As pessoas não têm a oportunidade de transformar "preocupações privadas em interesses públicos e lutas coletivas" (GIROUX, 2004, p. 494, tradução da autora), pois prevalece a individualidade e a meritocracia.

A doutrina neoliberal reforça ainda mais a estratificação social e as relações assimétricas de poder, acentuando a injustiça, a pobreza, o racismo, o sexismo e o capacitismo. Além disso, afasta a luta feminista de um processo libertador, coletivo, cooperativo e abolicionista. Como Dean (2009) escreveu: “o neoliberalismo é um programa econômico e político que beneficia apenas $1 \%$ da população mundial ao enviar bilhões para a pobreza” (p. 72, tradução da autora). Embora esta seja a realidade, a classe trabalhadora é levada a acreditar que se se esforçar e trabalhar muito, vai vencer: "o neoliberalismo promete que todos vão ganhar” (p. 72, tradução da autora), o que é de fato uma fantasia. Por isso, mais do que nunca nós precisamos de práticas alternativas e revolucionárias. 
Em contraponto a essa doutrina repressiva e neoliberal, é importante destacar o apelo para um feminismo para os 99\% como ocorreu durante a Greve Internacional das Mulheres em 2017². Feministas socialistas antirracistas estadunidenses estavam presente e esse foi um momento emblemático e necessário em tempos de neoliberalismo, pois como Eisenstein (2019) descreveu:

Era hora de se reunir com trabalhadoras de restaurantes, funcionárias do Wal-Mart, empregadas domésticas, mulheres imigrantes, mulheres negras e muitas outras. Algumas de nós usam véus, outras revelam seus rostos; algumas estão tatuadas, outras não; algumas são trans, alguns são indígenas, algumas são gays, outras são deficientes. Algumas são feitas de muitas dessas partes múltiplas. (p. 25, tradução da autora)

Além dos protestos massivos, acadêmicos(as), professores(as), pesquisadores(as) e ativistas também precisam trabalhar com pequenos grupos de educação popular para aprender com sua realidade e saberes socialmente construídos. Freire (FREIRE \& NOGUEIRA, 1993) entende a educação popular como mobilização, organização popular e do saber, e cita o exemplo de um grupo de mulheres da favela que se reunia aos sábados à tarde. Os sonhos delas eram gerados por suas lutas, saberes e esperança para transformarem seu contexto atual e terem um amanhã mais justo. No entanto, naqueles encontros, aquelas mulheres iam além de suas lutas individuais; aquelas mulheres, com sua facilitadora, lançavam um olhar sobre a sociedade como um todo e buscavam uma luta coletiva. Freire (FREIRE \& NOGUEIRA, 1993, p. 22) relatou que:

Naquelas reuniões, naqueles momentos discutidos se busca assuntos sobre elas e sobre a favela. E aí pode haver um 'corrimão' que é o seguinte: estamos nos reunindo ao redor de nossos temas e buscando mudanças mais amplas nessa sociedade em que sobrevivemos. OU SEJA, sem perder a noção e o gosto de reunir-se em torno de si mesmas, essas mulheres atingem uma inteligência maior de propor atitudes coletivas buscando o futuro que a esperança deseja.

Uma verdadeira educação popular, e também feminista e socialista, precisa transformar as queixas individuais em uma agenda coletiva, pois só assim haverá de fato uma mudança na sociedade. Dessa forma, vai-se contra os princípios de uma educação conservadora, individualista, competitiva e neoliberal. É no compartilhamento de suas insatisfações na vida privada e pública, e na escuta atenta das outras integrantes do grupo, que as mulheres se conscientizam criticamente. Para haver uma mudança duradoura nas relações sociais e no sistema econômico é preciso mudar as estruturas da sociedade e entender quem são os beneficiados pelo sistema capitalista patriarcal neoliberal e quem são os prejudicados. Como disse Freire (FREIRE \& NOGUEIRA, 1993), tudo vai sendo analisado e estudado num nível coletivo; as questões individuais são o ponto de partida, mas não o objetivo final.

O termo educação popular tem um significado especial na obra de Freire. De 1940 a 1963, surgiram no Brasil campanhas de alfabetização de jovens e adultos para áreas rurais e urbanas (SAVIANI, 2011). Naquela época, para votar, as pessoas precisavam ser alfabetizadas; daí o interesse dos governadores em transformar todo cidadão analfabeto em eleitor. Entretanto, a partir de meados da década de 1960, esse movimento passou a ter outro significado, assim como a educação que passou a ser uma forma de as massas participarem do processo político e se conscientizarem criticamente da realidade brasileira. Saviani (2011) explicou que a educação popular era uma educação que surgia do povo ao mesmo tempo que os beneficiava; já não era mais uma educação da elite ou dos governantes que costumavam usar a educação para manipular o povo.

Sobre isso, Saviani (2011) também afirmou que a concepção de educação popular estava alinhada com o conceito de educação elaborado por Freire. Ele escreveu que o movimento de educação popular desenvolvido por Freire impactou não só a educação no Brasil, mas também no exterior. Como tal, Freire nos deixou como legado uma educação que valoriza a leitura do mundo das pessoas. Esse processo de

\footnotetext{
${ }^{2}$ A Greve Internacional das Mulheres, de acordo com o site https://www.womenstrikeus.org/about-the-iws, é definida como "uma rede de mulheres cis e trans em mais de cinquenta países diferentes que surgiu por meio do planejamento de um dia de ação para 8 de março de 2017”. Essas mulheres têm como princípios comuns: 1) fim da violência de gênero; 2) justiça reprodutiva para todos; 3) direitos trabalhistas; 4) provisão social completa; 5) feminismo antirracista e anti-imperialista; e, 6) justiça ambiental para todos.
} 
leitura do mundo e leitura da palavra é possível por meio do diálogo entre educador(a) e educando(a) para que juntos(as), possam chegar a uma consciência crítica da realidade.

Como exemplo, há o trabalho realizado por Silva e Negretto (2017) na área de educação, vinculado ao ensino, pesquisa e extensão da Universidade Federal de Pelotas. Silva e Negretto (2017) apresentaram os resultados de uma pesquisa qualitativa feita com grupos de camponesas assentadas que fazem parte do Movimento dos Trabalhadores Rurais Sem Terra (MST) no município de Pinheiro Machado no sul do Brasil. O objetivo principal deste projeto foi construir uma pedagogia feminista que abordasse as questões de gênero e se pautasse nas obras de Freire sobre a educação popular. Negretto e Silva (2018) também compartilharam o resultado da pesquisa com mulheres de quatro assentamentos da Reforma Agrária, desde 2014, para problematizar as relações de gênero e poder vinculadas à divisão sexual do trabalho. Nesta pesquisa participativa que aborda os métodos de educação popular, feminista e de transformação social, Negretto e Silva (2018) ouviram as vozes das mulheres que contaram as histórias e estórias de suas vidas e trajetórias de trabalho. É interessante destacar que os homens também participaram das discussões sobre reprodução social - que atribui tarefas diferentes a homens e mulheres. As pesquisadoras usaram rodas de conversa, notas de campo e oficinas de artesanato e fotografia com as camponesas como ferramentas metodológicas para a coleta de dados. Os resultados mostraram que as mulheres camponesas buscam o reconhecimento de seu trabalho, pois percebem que o trabalho dos homens é mais valorizado. Uma das participantes disse: "Queria ser mais valorizada como esposa, como artesã e agricultora. Queria que me respeitassem mais” (p. 1199).

O projeto realizado com essas mulheres se baseia numa pedagogia feminista dentro de oficinas de produção artesanal. No entanto, a atividade artesanal não era um fim em si mesma, já que permitia que as mulheres repensassem suas trajetórias como mulheres no mundo e na história (SILVA \& NEGRETTO, 2017). Dito de outra forma, este não é um trabalho que termina na escuta das narrativas ou na leitura do mundo dessas mulheres. Em vez disso, as facilitadoras vão além e discutem o conhecimento sistematizado e crítico, ou a leitura da palavra, já produzido sobre a divisão de sexo/gênero do trabalho e o patriarcado. Assim, as participantes entendem criticamente como as mulheres foram oprimidas ao longo da história e como essa lógica sexista foi construída. Consequentemente, essas mulheres camponesas podem olhar suas experiências diárias de uma forma menos ingênua ou fatalista e entender como a lógica patriarcal e neoliberal opera em suas vidas. Assim, podem "repensar a partir do conhecimento da trajetória das mulheres no mundo e na história” (SILVA \& NEGRETTO, 2017, p. 2).

Esse trabalho realizado por Silva e Negretto (2017) nos mostra que juntas, teoria e prática, são cruciais para uma "educação libertadora para a consciência crítica” (HOOKS, 1991, p. 32, tradução da autora). As camponesas tornaram-se multiplicadoras desse processo e não meras aprendizes, uma vez que em seu espaço coletivo de trabalho, participaram de atividades como minicursos, palestras e debates sobre gênero e feminismo (SILVA \& NEGRETTO, 2017). Como podemos ver, "não é um processo individual, mas sim uma caminhada coletiva, de compromisso das mulheres com seu próprio processo emancipatório e de libertação (SILVA \& NEGRETTO, p. 6). Silva e Negretto (2017) também argumentaram que o patriarcado está diretamente conectado ao racismo e ao capitalismo, da mesma forma que Freire (FREIRE \& SHOR, 1986) afirmou que o racismo e o sexismo estão intimamente ligados ao capitalismo. Aquelas artesãs, por exemplo, não viam seu trabalho como um trabalho real, como o de seus maridos, embora o artesanato fosse sua fonte de renda. Afinal, para elas, artesanato era trabalho de mulher, assim como cuidar da casa e dos filhos. Segundo Silva e Negretto (2017), isso mostrou que

as atribuições dos papéis sociais a cada sexo, construído socialmente pelo patriarcado, explora e oprime a vida feminina, fazendo com que o trabalho doméstico, manual e artesanal, seja realizado pela mulher de forma naturalizada e invisível no ambiente privado, enquanto aos homens é reservado a atuação na esfera pública, gerando valorações distintas entre ambos. (p. 10)

As participantes compreenderam a divisão sexual do trabalho, o patriarcado e a supremacia masculina e, também, como desempenham papéis diferentes em comparação com os maridos e como o trabalho das mulheres é subestimado. Por meio de rodas de conversa, os lamentos e reclamações das participantes sobre as relações desiguais e opressoras entre homens e mulheres foram transformados em "pautas de lutas feministas” (SILVA \& NEGRETTO, 2017, p. 13) para que lutassem pela igualdade, expressassem 
suas vozes no processo de tomada de decisões, participassem dos lucros da casa e, certamente, lutassem pelo simples direito de serem felizes. Nessa jornada, Silva e Negretto (2017) criaram com as artesãs todo o processo de aprendizagem, sem tentar impor um pacote de informações previamente construído. As rodas de conversa, reminiscentes dos círculos de cultura de Freire, mostram o rigor do trabalho das autoras por seguirem a práxis de uma educação popular freireana.

Deve se notar que os círculos de cultura foram um modelo de educação que Freire usou para ensinar criticamente os trabalhadores camponeses fora do modelo de escola tradicional. Os círculos de cultura eram formados por um educador dialógico e problematizador, não por um professor narrador que depositava conteúdo na cabeça vazia dos alunos. Homens e mulheres, juntos, educavam-se (FREIRE, 2001a; LYRA, 2006). Essa prática é exatamente o que se vê nessas rodas de conversa, que identifico como uma educação popular, feminista e socialista. Isso significa que, nesta atividade de educação popular, as facilitadoras abordaram temas como gênero e questões sociais, e eu sugiro que trabalhos futuros nesta área abordem questões queer, de raça/etnia e capacitismo, a fim de se ouvir uma pluralidade de vozes e se ter uma perspectiva interseccional da realidade. O diálogo deve incluir uma escuta genuína tanto na teoria quanto na prática, e o papel de uma educação popular, feminista e também socialista é precisamente preencher essa lacuna.

Assim como Silva e Negretto (2017), Castro (2014) realizou um trabalho semelhante e apresentou os resultados de sua pesquisa de doutorado. O objetivo principal foi verificar como ocorria o processo informal, ou de educação popular, de ensino e aprendizagem com tecelãs no município de Resende Costa, em Minas Gerais. Desde 1950, as mulheres desta pequena cidade têm visto na tecelagem uma forma de ganhar dinheiro e, ao mesmo tempo, de cuidar da família e da casa. Portanto, esse tipo de trabalho tem sido passado de geração em geração por meio de uma educação não formal, ainda uma forma de educação, e entendida como aquela que as pessoas aprendem enquanto socializam. O processo de ensino-aprendizagem ocorre "no mundo da vida” (p. 2) dessas trabalhadoras, por isso é uma educação popular e feminista. Não ocorre, por exemplo, no mundo das paredes da escola formal, onde os alunos são vigiados e avaliados constantemente. Infelizmente, como Silva e Negretto (2017) confirmaram, Castro (2014) também descobriu que o sistema patriarcal desconsidera e não valoriza o trabalho feito pelas mulheres. Por isso, a contribuição da educação popular e do feminismo é fundamental para essas mulheres, para que valorizem sua criação de conhecimento e diálogo entre elas e o mundo. Elas devem atingir uma consciência crítica da situação histórica, econômica, cultural e social da sociedade em que vivem, e como o patriarcado afeta suas vidas. Além disso, o conhecimento vem da leitura do mundo (FREIRE, 2002, p. 138), por meio de suas próprias narrativas, e acaba se tornando uma luta por emancipação, ou seja, sua própria libertação no sentido freireano.

Além dos exemplos de educação popular e feminista no Brasil, e que também considero socialista por buscarem formas mais justas de trabalho e renda para as mulheres, apresento brevemente práticas desenvolvidas no Canadá (HANSON, 2015), Estados Unidos (RIVERA, 2004) e Bolívia (KOLLINS, \& HANSMAN, 2005), fundamentadas na obra de Freire.

O primeiro exemplo é a Prairie School for Union Women (PSUW) em Saskatchewan, Canadá. Esta escola de trabalho usa a educação popular feminista, a aprendizagem não formal de adultos, a relação universidade-comunidade e práticas ativistas para aprofundar o conhecimento sobre os movimentos trabalhistas e construir a solidariedade entre as mulheres trabalhadoras. Por meio de uma pesquisa de ação participativa feminista e comunitária, Hanson (2015) entrevistou e organizou um grupo focal com 20 mulheres que frequentavam a escola. Os resultados mostraram que a educação popular feminista daquela escola permitiu uma transformação na vida de muitas das mulheres: “As histórias expressas pelas participantes do estudo indicam que a transformação é vivida nas perspectivas pessoais e na construção da confiança entre as mulheres individualmente” (p. 13, tradução da autora). Estar nessa escola de trabalho com uma prática pedagógica popular e feminista (e socialista) permitiu que essas mulheres se tornassem solidárias, politicamente conscientes e mais confiantes em suas identidades como feministas, aborígines, lésbicas e portadoras de deficiência física.

O próximo exemplo vem de um estudo etnográfico de cinco anos realizado por Rivera (2004) em um programa de educação popular baseado em abrigos para famílias em Boston, Estados Unidos. Rivera (2004) mostrou que uma educação popular feminista ajudou a construir um senso de comunidade entre um 
grupo de 50 women of color sem-teto e também abordou as causas profundas da pobreza. Os resultados indicaram que essas mulheres não só foram alfabetizadas, como também "se engajaram em estilos de vida mais saudáveis, investiram mais na educação dos filhos, melhoraram seu status socioeconômico e aumentaram sua participação cívica” (p. 196, tradução da autora) e buscaram ser protagonistas de suas vidas em busca de justiça social.

O último exemplo, mas não menos importante, é sobre uma organização de educação popular de base comunitária, o escritório de educação da Oficina Jurídica Para la Mujer, em Cochabamba, Bolívia. Por meio de uma metodologia de estudo de caso, Kollins e Hasman (2005) investigaram como os programas de educação popular transformaram a vida de mulheres que precisam desafiar as normas sociais do status quo e desenvolver consciência crítica. Três participantes do programa, um promotor de graduação e um facilitador do programa foram entrevistados. Os resultados revelaram que o programa melhorou a autoestima das mulheres para conhecer seus direitos; as mulheres foram capazes de redesenhar seus papéis de gênero e relacionamentos na família; e se tornaram defensoras dos direitos humanos em suas comunidades. Além do impacto da educação popular comunitária na vida individual, familiar e comunitária, o programa mostrou que as mulheres passaram a compreender a necessidade de uma mudança social em larga escala.

Foi possível perceber a partir dessas histórias compartilhadas por mulheres no Brasil, Canadá, Estados Unidos e Bolívia que uma educação feminista, popular e, mesmo não sendo nomeada, eu diria, socialista, permite que as vozes das mulheres, trabalhadoras e de grupos mais pobres e marginalizados da sociedade, sejam genuinamente ouvidas. Como Negretto e Silva (2018) escreveram com precisão: "É nas relações intrínsecas das rodas de conversa, nas texturas, entre as sucatas, os tecidos e as agulhas que mais relatos sobre a ‘vida vivida’ são trazidos à tona com forte significado pessoal” (p. 1190-1191). Entretanto, o mais importante, é expandir e as narrativas e transformá-las em uma busca por justiça social e uma agenda coletiva para acabar com a opressão e a exploração das mulheres por meio de uma rede transnacional, feminista, socialista, popular e solidária.

Vale destacar que não havia hierarquia entre as facilitadoras e participantes dos grupos de educação popular mencionados, o que mostra que se tratava de uma prática libertadora e dialógica. Tendo um lugar seguro para falar e ouvir, as mulheres puderam compreender melhor o contexto histórico, social e cultural em que habitavam, as relações de poder embutidas em suas vidas diárias, e o capitalismo e o patriarcado não como conceitos abstratos, mas como uma linguagem que se traduz em seu cotidiano. Como hooks (1991) disse: “devemos continuamente reivindicar a teoria como prática necessária dentro de uma estrutura holística de ativismo libertador” (p. 33, tradução da autora). É importante deixar claro que tanto a leitura do mundo quanto a leitura da palavra, assim como a prática e a teoria, desempenham um papel fundamental na libertação das mulheres.

A práxis feminista e socialista é forjada a partir de lutas, explorações e opressões que as mulheres vivenciam: "As feministas lidam diretamente com suas próprias vidas diárias - algo que explica a rápida disseminação desse movimento” (HARTSOCK, 1979, p. 59, tradução da autora). Igualmente, uma pedagogia popular e socialista das mulheres oprimidas têm como ponto de partida a luta cotidiana das pessoas envolvidas, para a partir daí compreender a história e as estruturas de opressão, que é o que Freire (2002) chamou de leitura de mundo e leitura da palavra. É lendo o mundo, ou seja, o conhecimento criado socialmente, e lendo a palavra, o conhecimento sistematizado, que mulheres e homens podem se tornar conscientemente críticos(as) do contexto em que vivem e, assim, transformá-lo. É desse modo principalmente que as mulheres podem re(ver) sua realidade de uma forma menos ingênua e mais crítica: "O movimento das mulheres está trabalhando nessas duas tarefas - a primeira insistindo que toda mulher pode reconstruir os argumentos feministas mais gerais por conta própria, a segunda recorrendo aos escritos de intelectuais mais tradicionais para qualquer orientação que possamos encontrar lá” (HARTSOCK, 1979, p. 67, tradução da autora). É nessa relação dialética entre teoria e prática (práxis), leitura do mundo e da palavra, que o movimento ganha força, sentido e, sobretudo, respeito às preocupações e ao intelecto das mulheres.

A revolução na direção de uma sociedade socialista é um caminho sinuoso, com erros e acertos. Ainda assim, Davis (1983) argumentou que a luta das mulheres trabalhadoras, que exigem as mesmas condições que os homens e creches públicas, pode “conter um potencial revolucionário explosivo” (p. 
244, tradução da autora). Isso seria, para Davis (1983), uma das estratégias para caminhar em direção ao socialismo. Portanto, há uma necessidade urgente de desmantelar esses sistemas hierárquicos opressores para que, nesses espaços de educação popular, feminista e socialista, as mulheres possam refletir criticamente e discutir as condições de opressão através das lentes intersetoriais de classe, gênero/sexo, raça/etnia e capacitismo.

\section{OBSERVAÇ̃̃ES FINAIS}

O caminho percorrido por mulheres que conhecem e (re)conhecem sua história e as implicações sociais, econômicas e culturais de serem negras, indígenas, imigrantes, com alguma deficiência física ou psicológica, queer, rurais, artesãs, sem-teto, alfabetizadas (ou não) e/ou da classe trabalhadora é complexo e tortuoso. Sabemos para onde partir, mas não exatamente como isso vai se concretizar numa sociedade mais justa, que, entre outras coisas, visa o fim da opressão contra as mulheres. Freire (2005) escreveu que após a transformação da realidade, a pedagogia não seria mais dos oprimidos e das oprimidas, mas de todas as pessoas num processo constante de libertação. É por isso que ele argumentou que a libertação é um processo doloroso, como um parto. Afinal, nasce um novo ser: nem opressor(a) nem oprimido(a), mas um novo ser humano em fase de libertação.

Para concluir, o diálogo entre o feminismo socialista e uma pedagogia das mulheres oprimidas nutre nossa esperança crítica por um mundo mais justo. A expansão e atualização dessas teorias e práticas nos mostra que uma educação popular, feminista e socialista não só é viável, mas também fundamental se quisermos desmantelar as várias faces da opressão, especialmente agora em tempos de capitalismo neoliberal global e patriarcal.

\section{REFERÊNCIAS}

ANDREOLA, B. A. Paulo Freire e a Condição da Mulher. Roteiro, Joaçaba, v. 41, n. 3, p. 609-628, set./ dez. 2016. doi:10.18593/r.v41i3.10398

CASTRO, A. M. Educação Popular e Estudos Feministas: Problematizando a produção de tecelãs. Revista Unifreire, 2, p. 23-28, 2014. Disponível em <http:/acervo.paulofreire.org:8080/jspui/ bitstream/7891/3465/1/FPF_PTPF_01_0450.pdf> Acesso em 20 de ago. de 2020.

CRENSHAW, K. Mapping the margins: Intersectionality, identity politics, and violence against women of color. Stanford Law Review, v. 43, n. 6, p. 1241-1299, jul., 1991.

DAVIS, A. Y. Women, Race and Class (1st Vintage Books ed.). New York, NY: Vintage Books, 1983.

DEAN, J. Democracy and Other Neoliberal Fantasies: Communicative capitalism and left politics. Durham, NC: Duke University Press Books, 2009.

EISENSTEIN, Z. R. Developing a theory of capitalist patriarchy and socialist feminism. In: Capitalist Patriarchy and the Case for Socialist Feminism. New York, NY: Monthly Review Press, 1979a, p. 5-40.

EISENSTEIN, Z. R. Introduction. In: Capitalist Patriarchy and the Case for Socialist Feminism. New York, NY: Monthly Review Press, 1979b, p. 1-4.

EISENSTEIN, Z. R. Some notes on the relations of capitalist patriarchy. In: Capitalist Patriarchy and the Case for Socialist Feminism. New York, NY: Monthly Review Press, 1979c, p. 41-55.

EISENSTEIN, Z. R. Abolitionist Socialist Feminism: Radicalising the next revolution. New York, NY: Monthly Review Press, 2019.

FRASER, N. Fortunes of feminism: from state-managed feminism to neoliberal crisis. Brooklyn, NY: Verso Books, 2013. 
FREIRE, P. The Politics of Education: Culture, power and liberation. (D. Macedo, Trans.). Westport, CT: Bergin \& Garvey, 1985.

FREIRE, P.; NOGUEIRA, N. Que Fazer: Teoria e prática em educação popular. Petrópolis, RJ: Vozes, 1993.

FREIRE, P. Conscientização: Teoria e prática da libertação - uma introdução do pensamento de Paulo Freire. São Paulo, SP: Centauro, 2001a.

FREIRE, Paulo. Professora Sim, Tia Não: cartas a quem ousa ensinar. São Paulo: Olho d’água, 2001b.

FREIRE, P. Pedagogia da Autonomia. São Paulo, SP: Paz e Terra, 2002.

FREIRE, P. Pedagogia do Oprimido. Rio de Janeiro: Paz e Terra, 2005.

FREIRE, P. Pedagogia da Esperança. São Paulo: Paz e Terra, 2009.

FREIRE, P. El Grito Manso. México: Siglo XXI, 2010.

FREIRE, P. Pedagogia dos Sonhos Possíveis. São Paulo, SP: Paz e Terra, 2014.

FREIRE, P.; SHOR, I. Medo e Ousadia: o cotidiano do professor. Rio de Janeiro: Paz e Terra, 1986.

GIROUX, H. A. Public Pedagogy and the Politics of Neo-liberalism: making the political more pedagogical. Policy Futures in Education, v. 2, n. 3 \& 4, p. 494-503, 2004.

HANSON, C. "I learned I am a feminist": Lessons for adult learning from participatory action research with union women. The Canadian Journal for the Study of Adult Education (Online), v. 2, n. 1, p. 1-15, 2015.

HARTSOCK, N. Feminist theory and the development of revolutionary strategy. In Z. R. Eisenstein, Capitalist Patriarchy and the Case for Socialist Feminism. New York, NY: Monthly Review Press, 1979, p. 56-77

HOOKS, B. Theory as liberatory practice. Yale Journal of Law and Feminism, v. 4, n. 1, p. 27-33, 1991.

HOOKS, B. Bell hooks speaking about Paulo Freire-the man, his work. In P. Leonard \& P. McLaren (Eds.), Paulo Freire: A critical encounter. London, UK: Routledge, 1993, p. 122-127.

JAGGAR, A. M. Feminist politics and Human Nature. Totowa, NJ: Rowman and Littlefield, 1988.

LYRA, C. As Quarenta Horas de Angicos: uma experiência pioneira de educação. São Paulo, SP: Cortez, 1996.

KOLLINS, J. M., HANSMAN, C. A. The Role of Women in Popular Education in Bolivia: A case study of the oficina jurídica para la mujer. Adult Basic Education, v. 15, n. 1, p. 3-20, 2005.

MOHANTY, C. T. Feminism without Borders: Decolonizing theory, practicing solidarity. Durham, NC: Duke University Press, 2003.

NEGRETTO, C., SILVA, M. A. Problematizando o Trabalho Invisível das Mulheres e a Divisão Sexual de Trabalho no Campo: Uma parceria entre educação popular e feminismo. Revista Brasileira de Educação do Campo, v. 3, n. 4, p. 1184-1201, 2018.

PROFESSORA recebe segunda denúncia por citar Paulo Freire. Diário do Centro de Mundo, São Paulo, 31 de jan. 2019. Disponível em: <https://www.diariodocentrodomundo.com.br/professorarecebe-segunda-denuncia-por-citar-paulo-freire/> Acesso em 08 de ago. de 2020.

RIVERA, L. Learning community: Popular education and homeless women. Women's Studies Quarterly, v. 32, n. 1/2, p. 196-212, 2004.

OSBORNE, S. Bolsonaro regime to remove Brazilian textbook references to feminism and homosexuality. Independent, United Kingdon, 12 fev. 2019. Disponível em: https://www.independent.co.uk Acesso em 08 de ago. de 2020. 
SALDAÑA, P. Bolsonaro's education plan means to expurge Paulo Freire's influence from the school system. Folha de S. Paulo, São Paulo, 07 jan. 2019. Disponível em: https://www1.folha.uol.com.br/ internacional/en/brazil Acesso em 08 de ago. de 2020.

SAVIANI, D. História das Ideias Pedagógicas no Brasil. Campinas: Autores Associados, 2011.

SILVA, M. A., NEGRETTO, C. Saberes e Fazeres de Mulheres na Construção de uma Pedagogia Feminista. XXXI Congresso ALAS: Las encrucijadas abiertas de América Latina, la sociología en tiempos de cambio, Montevideo. Uruguai, 2017. Anais. Disponível em: http://alas2017.easyplanners. info/opc/tl/6017_marcia_alves_da_silva.pdf. Acesso em 15 de nov. de 2018.

VIEZZER, M. L. Paulo Freire e as Relações Sociais de Gênero. In: M. Gadotti (Ed.), Paulo Freire: Uma biobibliografia. São Paulo, SP: Cortez Editora e Instituto Paulo Freire, 1996, p. 596-598.

YOUNG, I. M. Justice and the Politics of Difference. Princeton, NJ: Princeton University Press, 2011. 